\title{
Comportamento ingestivo de vacas em lactação alimentadas com cana-de-açúcar ou feno da parte aérea da mandioca
}

\author{
[Ingestive behavior of dairy cows fed sugar cane or cassava aerial portion hay] \\ A.L. Rocha Neto ${ }^{1}$, C.M. Veloso ${ }^{2}$, F.F. Silva ${ }^{3}$, D.R. Souza ${ }^{3}$, L.T. Costa ${ }^{4}$, R.M. Murta ${ }^{3}$, R.R. Silva ${ }^{3}$, \\ J.C.P.M. Silva, D.D. Souza ${ }^{3}$, M.A. Meneses ${ }^{3}$ \\ ${ }^{1}$ Instituto Federal Baiano - Campus Santa Inês - Santa Inês, BA \\ ${ }^{2}$ Universidade Federal de Viçosa - Viçosa, MG \\ ${ }^{3}$ Universidade Estadual do Sudoeste da Bahia - UESB - Itapetinga, BA \\ ${ }^{4}$ Zootecnista autônomo \\ RESUMO
}

\begin{abstract}
Avaliou-se o efeito de dietas com cana-de-açúcar ou diferentes porcentagens de inclusão de feno da parte aérea da mandioca (FPAM) sobre o comportamento ingestivo de vacas leiteiras. Utilizaram-se 16 vacas, sendo $12 \mathrm{em}$ lactação e quatro secas, fistuladas, distribuídas em quatro quadrados latinos $4 \times 4$. As dietas foram formuladas na tentativa de serem isoenergéticas, com quatro porcentagens de FPAM na dieta 0, 33, 67 e 100\% da MS total da dieta, em substituição à cana-de-açúcar tratada com 1\% de uma mistura de ureia e sulfato de amônio (9:1 partes). O comportamento ingestivo foi avaliado durante 24 horas consecutivas, sendo as observações efetuadas em intervalos de cinco minutos. Foi observado efeito quadrático $(\mathrm{P}<0,05)$ sobre os consumos de matéria seca e fibra em detergente neutro, por dia e por período de alimentação, sobre as atividades de alimentação, ruminação, mastigação e ócio, bem como sobre as eficiências de alimentação e ruminação. Não foi apresentada diferença $(\mathrm{P}>0,05)$ para os números e períodos de alimentação e ruminação. A avaliação do comportamento ingestivo constitui ferramenta de mensuração da quantidade e qualidade das dietas consumidas, uma vez que demonstra a resposta ingestiva dos bovinos à dieta fornecida.
\end{abstract}

Palavras-chave: vaca leiteira, mandioca, ruminação, etologia

\begin{abstract}
The effect of diets containing sugar cane or different percentages of cassava aerial portion hay (FPAM) inclusion on dairy cows ingestion behavior was evaluated. Sixteen cows were used, including twelve lactating and four dry, which were fistulated and divided into four $4 \times 4$ Latin squares. Diets were formulated in an attempt to be isoenergetic, with four percentages of FPAM in the diet (0,33,67 and 100\% of diet total DM), replacing the sugar cane treated with 1\% of a mixture of urea and ammonium sulfate (9:1 parts). The ingestion behavior was evaluated for 24 consecutive hours, with observations at five minute intervals. A quadratic effect $(P<0.05)$ on dry matter and neutral detergent fiber intake, per day and feeding period, on feeding, ruminating, chewing and idle activities, as well as on feeding and ruminating efficiencies, with no difference $(P>0,05)$ for numbers and periods of feeding and rumination was observed. The ingestion behavior evaluation constitutes a tool for measuring the amount and quality of diets consumed, since it demonstrates their ingestion response by cattle diet provided.
\end{abstract}

Keywords: dairy cows, cassava, rumination, ethology

\section{INTRODUÇÃO}

A cana-de-açúcar tem sido utilizada como recurso forrageiro, há décadas, por apresentar vantagens como elevada produção de matéria seca por área, disponibilidade no período seco do ano, baixo custo de produção em relação às culturas de milho e sorgo e facilidade de cultivo. Além disso, o conhecimento sobre o uso e a correção das deficiências nutricionais dessa forragem permitiu a massificação de sua

Recebido em 17 de agosto de 2011

Aceito em 20 de julho de 2012

E-mail: aires21@bol.com.br 
utilização na alimentação de bovinos de leite (Oliveira et al., 2007a).

Durante muito tempo, produtores, técnicos e pesquisadores procuraram melhorias na produção de volumosos, que é um dos fatores responsáveis pelo sucesso da cadeia produtiva de leite e de carne no Brasil, ao tentarem encontrar equilíbrio econômico da atividade e aspectos de produção e produtividade. $\mathrm{O}$ aumento do uso da cana-deaçúcar na alimentação de bovinos tem como motivo o elevado potencial de produção de massa, 80 a 120ton/ha, e de energia, 15 a 20 ton de NDT/ha. Mesmo sabendo do alto potencial da cana-de-açúcar, não se pode ficar restrito apenas a este alimento. ,É preciso, portanto, estudar alternativas de volumoso para ser utilizado com sucesso na alimentação animal. Entre estes volumosos, tem-se a parte aérea da mandioca, que corresponde a toda porção da planta que se encontra acima do solo e corresponde a, aproximadamente, $50 \%$ do peso fresco dela, sendo composta por talos e pecíolos (40\%) e folhas (10\%). Por este motivo, a parte aérea da mandioca se caracteriza por apresentar maiores teores de fibra e proteína, enquanto as raízes apresentam elevados teores de carboidratos não estruturais. Desta forma, pode ser considerada um volumoso relativamente rico em proteínas e com quantidades apreciáveis de carboidratos não estruturais (Marques e Caldas Neto, 2002).

A parte aérea da mandioca pode ser utilizada na forma fresca, ensilada ou na forma de feno, com composição variável em razão da proporção de caules e folhas. Pode ser usada na alimentação animal, pois seu valor nutritivo e produção por área são bons (Modesto et al., 2004).

O estudo do comportamento ingestivo é uma ferramenta de grande importância na avaliação das dietas, por possibilitar ajustar o manejo alimentar dos animais para obtenção de melhor desempenho produtivo (Mendonça et al., 2004). Segundo Dado et al. (1995), o comportamento ingestivo do animal é constituído pelos tempos de alimentação, ruminação, ócio, eficiência de alimentação e ruminação. $\mathrm{O}$ comportamento ingestivo pode influenciar a digestão dos alimentos e sua taxa de passagem pelo trato gastrintestinal dos ruminantes. Porém, os animais podem alterar seu comportamento ingestivo, modificando um ou mais dos seus componentes para superar condições limitantes ao consumo e obter a quantidade de nutrientes necessária.

O presente trabalho foi realizado com o objetivo de avaliar o comportamento ingestivo de vacas em lactação alimentadas com dietas à base de cana-de-açúcar ou feno da parte aérea de mandioca, produzidas sob sistema de plantio adensado.

\section{MATERIAL E MÉTODOS}

$\mathrm{O}$ experimento foi realizado em uma fazenda particular, localizada no município de Macarani, Bahia, e no Laboratório de Forragicultura e Pastagens da Universidade Estadual do Sudoeste da Bahia, no campus de Itapetinga, Bahia. Foram utilizadas 16 vacas mestiças Holandês x Zebu, grau de sangue variando de $1 / 2$ a $3 / 4$ de sangue Holandês, sendo quatro fistuladas no rúmen, de terceira ou quarta lactação, com produção anterior entre 2.500 e $3.000 \mathrm{~kg}$, ajustada para 300 dias, com peso corporal médio de $470 \mathrm{~kg} \pm 34 \mathrm{~kg}$, 60 dias, em média, de lactação, no início do período experimental, e distribuídas em quatro quadrados latinos $4 \times 4$.

Entre os dias 27 de novembro de 2009 e 22 de janeiro de 2010, os animais foram alojados em baias individuais cobertas, providas de cocho individual de concreto para alimentação e bebedouro de concreto com boia, comum a duas baias. Os quatro tratamentos foram constituídos de diferentes porcentagens de feno da parte aérea da mandioca (FPAM), produzida sob sistema de plantio adensado, na dieta 0;33; 67 e 100\% da MS total da dieta, em substituição à cana-deaçúcar, variedade RB 72-454, tratada com $1 \%$ de uma mistura de ureia e sulfato de amônio (9:1 partes). Foi definido, pelo balanceamento das dietas, que elas teriam nutrientes suficientes para mantença e produção de $15 \mathrm{~kg}$ de leite/dia, de acordo com o NRC (Nutrient..., 2001), com base nos dados da análise bromatológica da cana-deaçúcar e do FPAM, previamente feita no início do experimento.

Durante todo o período experimental, diariamente, às seis e às 15 horas, a cana-de-açúcar foi desintegrada em máquina desintegradora. A cana-de-açúcar, no momento do fornecimento aos animais, foi corrigida com $1,0 \%$ da mistura ureia/sulfato de amônio (9:1), na base da matéria natural. Nesse procedimento, 
a ureia foi previamente pesada, de acordo com a quantidade de cana-de-açúcar estimada em cada tratamento, para o fornecimento diário. Posteriormente, foram pesadas as quantidades de FPAM e concentrado, de acordo com a quantidade recomendada para cada tratamento.

As proporções estimadas dos ingredientes nos concentrados são apresentadas na Tab. 1, na base da matéria natural.

O experimento teve duração de 56 dias, divididos em quatro períodos de 14 dias, sendo nove dias de adaptação às dietas e cinco dias de coleta. As dietas foram fornecidas à vontade, duas vezes ao dia, às sete e às 16 horas, e ajustadas de forma a manter as sobras em torno de 5 a $10 \%$ do fornecido, com água permanentemente à disposição dos animais. Durante o experimento, os alimentos oferecidos foram registrados diariamente. No período de coleta, do $10^{\circ}$ ao $14^{\circ}$ dia, amostras dos volumosos, do concentrado e das sobras de cada animal foram coletadas diariamente, acondicionadas em sacos plásticos e armazenadas em freezer.

Tabela 1. Proporção dos ingredientes nos concentrados, na base da matéria natural

\begin{tabular}{lcccc}
\hline \multirow{2}{*}{ Ingrediente (\%) } & \multicolumn{4}{c}{ Inclusão do feno da parte aérea da mandioca (\%) } \\
\cline { 2 - 5 } & 0 & 33 & 67 & 100 \\
\hline Milho grão moído & 64,34 & 80,04 & 89,12 & 95,27 \\
Farelo de soja $^{1}$ & 29,39 & 14,66 & 5,88 & ---- \\
Sal mineral $^{1}$ & 3,48 & 3,50 & 3,51 & 3,31 \\
Fosfato bicálcico $^{\text {Calcário calcítico }}$ & 2,00 & 1,80 & 1,50 & 1,42 \\
\hline
\end{tabular}

${ }^{1}$ Composição: cálcio, 18,5\%; fósforo, 9\%; magnésio, 0,4\%; enxofre, 1\%; sódio, 11,7\%; selênio, 30ppm; cobre, 1500ppm; zinco, 4000ppm; manganês, 1200ppm; iodo, 150ppm; cobalto, 150ppm.

A composição química bromatológica e os nutrientes digestíveis totais estimados da canade-açúcar + ureia do feno da parte aérea da mandioca (FPAM) e dos concentrados na base da matéria seca encontram-se na Tab. 2.

Tabela 2. Composição química bromatológica e nutrientes digestíveis totais estimados da cana-de-açúcar + ureia do feno da parte aérea da mandioca (FPAM) e dos concentrados na base da matéria seca

\begin{tabular}{lcccccc} 
& & & \multicolumn{4}{c}{ Concentrado dos tratamentos em razão dos } \\
Item $(\%)$ & Cana+ureia & FPAM & \multicolumn{4}{c}{ níve fe FPAM $(\%)$} \\
\cline { 3 - 6 } & & & 0 & 33 & 67 & 100 \\
\hline MS & 23,14 & 84,41 & 89,35 & 89,23 & 88,97 & 88,91 \\
MO & 95,48 & 93,39 & 90,06 & 92,20 & 93,27 & 89,70 \\
PB & 15,18 & 21,26 & 18,43 & 14,01 & 11,34 & 9,46 \\
NIDN & 7,90 & 61,52 & 59,32 & 49,53 & 37,87 & 39,42 \\
NIDA & 5,09 & 33,46 & 33,46 & 24,42 & 24,15 & 23,74 \\
CT & 79,45 & 68,45 & 68,83 & 75,00 & 78,90 & 76,76 \\
FDN & 54,71 & 62,97 & 37,00 & 33,81 & 34,90 & 38,49 \\
FDNcp & 51,38 & 43,95 & 22,73 & 23,70 & 27,75 & 28,67 \\
CNF & 24,74 & 5,48 & 31,83 & 41,19 & 44,00 & 38,27 \\
Lig & 5,46 & 21,55 & 0,69 & 0,93 & 1,07 & 1,45 \\
FDNi & 25,72 & 23,96 & 2,56 & 2,34 & 2,02 & 2,61 \\
NDTest & 57,21 & 33,46 & 77,49 & 64,06 & 66,90 & 60,90 \\
Brix & 18,00 & --- & --- & --- & --- & -- \\
\hline
\end{tabular}

MS- matéria seca, MO- matéria orgânica, PB- proteína bruta, NIDN- nitrogênio insolúvel em detergente neutro, porcentagem do nitrogênio total, NIDA- nitrogênio insolúvel em detergente ácido, porcentagem do nitrogênio total, CT- carboidratos totais (100 - \%PB +\%EE +\%MM) (Sniffen et al., 1992), FDN- fibra em detergente neutro, FDN $\mathrm{CP}^{-}$ fibra em detergente neutro corrigida para cinza e proteína, CNF- carboidratos não fibrosos $(100-(\% \mathrm{~PB}+\% \mathrm{EE}+$ $\% \mathrm{MM}+\% \mathrm{FDN}$ ) (Sniffen et al., 1992), LIG- lignina, FDNi- fibra em detergente neutro indigestível, NDTestnutrientes digestíveis totais, valores estimados por Detmann et al. (2006a, 2006b, 2006c, 2007a), BRIX-concentração de açúcares solúveis na cana-de-açúcar. 
Amostras dos volumosos, dos concentrados e das sobras de cada animal foram pré-secas em estufa com ventilação forçada a $60^{\circ} \mathrm{C}$ e moídas em moinho de faca peneira com crivos de $1 \mathrm{~mm}$ para posteriores análises químicas.

Foi estimado o consumo de MS e FDN em $\mathrm{kg} /$ dia.
As análises de matéria seca (MS) e fibra em detergente neutro (FDN) foram realizadas seguindo os procedimentos descritos em Silva e Queiroz (2002).

$\mathrm{Na}$ Tab. 3, encontram-se a relação volumoso:concentrado (V:C) e a composição química das dietas fornecidas nos quatro tratamentos, com base na matéria seca.

Tabela 3. Relação volumoso:concentrado (V:C) e composição química das dietas fornecidas nos quatro tratamentos, com base na matéria seca

\begin{tabular}{lcccc}
\hline \multirow{2}{*}{ Item(\%) } & \multicolumn{4}{c}{ Inclusão do feno da parte aérea da mandioca $(\%)$} \\
\cline { 2 - 4 } \multicolumn{1}{c}{ Relação V:C } & 0 & 33 & 67 & 100 \\
\cline { 2 - 4 } MS & $74,5: 25,4$ & $74,6: 25,3$ & $74,6: 25,3$ & $73,6: 26,3$ \\
MO & 39,99 & 55,11 & 70,40 & 85,60 \\
PB & 94,10 & 94,13 & 93,88 & 92,42 \\
NIDN & 16,00 & 16,39 & 17,24 & 18,15 \\
NIDA & 20,99 & 31,77 & 42,26 & 55,69 \\
CT & 12,31 & 17,04 & 24,08 & 30,90 \\
FDN & 76,75 & 75,59 & 72,82 & 70,64 \\
FDNcp & 50,20 & 51,47 & 53,81 & 56,51 \\
CNF & 44,09 & 42,53 & 41,68 & 39,92 \\
Lig & 26,55 & 24,12 & 20,01 & 14,12 \\
FDNi & 4,25 & 8,32 & 12,38 & 16,25 \\
NDT & 19,82 & 19,36 & 18,84 & 18,33 \\
\hline
\end{tabular}

MS- matéria seca, MO- matéria orgânica, PB- proteína bruta, NIDN- nitrogênio insolúvel em detergente neutro, porcentagem do nitrogênio total, NIDA- nitrogênio insolúvel em detergente ácido, porcentagem do nitrogênio total, CT- carboidratos totais $(100-(\% \mathrm{~PB}+\% \mathrm{EE}+\% \mathrm{MM}))($ Sniffen et al., 1992), FDN- fibra em detergente neutro, $\mathrm{FDN}_{\mathrm{CP}}$ fibra em detergente neutro corrigida para cinza e proteína, CNF- carboidratos não fibrosos (100 - $(\% \mathrm{~PB}+$ $\% \mathrm{EE}+\% \mathrm{MM}+\% \mathrm{FDN})$ ) (Sniffen et al., 1992), LIG- lignina, FDNi- fibra em detergente neutro indigestível, NDTnutrientes digestíveis totais

$\mathrm{Na}$ avaliação do comportamento ingestivo, as vacas submetidas a períodos de observação visual no $14^{\circ}$ dia foram observadas durante 24 horas, em intervalos de cinco minutos, para avaliação dos tempos de alimentação, ruminação e ócio. Neste mesmo dia, foram realizadas quatro observações de cada animal, em quatro períodos diferentes: manhã, tarde, noite e madrugada. Foi avaliado, nesses períodos, o número de mastigações por bolo ruminal e contabilizado o tempo gasto para ruminação de cada bolo. Esse procedimento foi realizado com o auxílio de cronômetros digitais, manuseados por quatro observadores, que se posicionaram em frente às baias, de forma a não incomodar os animais. Durante a observação noturna, o ambiente foi mantido com iluminação artificial (Bürguer et al., 2000).
$\mathrm{Na}$ estimativa das variáveis comportamentais alimentação e ruminação (min/dia), eficiência alimentar (g MS e FDN/hora), eficiência de ruminação (g de MS e FDN/bolo e g de MS e FDN/hora) e consumo médio de MS e FDN por período de alimentação, considerou-se o consumo voluntário de MS e FDN por período de alimentação (Bürguer et al., 2000).

O número de bolos ruminais, diariamente, foi obtido da seguinte forma: tempo total de ruminação ( $\mathrm{min}$ ) dividido pelo tempo médio gasto na ruminação de um bolo. A concentração de MS e FDN em cada bolo (g) foi multiplicada pelo número de bolos ruminados diariamente (Silva et al., 2006). 
A eficiência de alimentação e ruminação foi obtida por:

EALMS $=$ CMS/TAL e

EALFDN= CFDN/TAL, em que:

EALMS (g MS consumida/h); EALFDN (g FDN consumida $/ \mathrm{h})=$ eficiência de alimentação; CMS $(\mathrm{g})=$ consumo diário de matéria seca; CFDN $(\mathrm{g})=$ consumo diário de fibra em detergente neutro; $\mathrm{TAL}=$ tempo gasto diariamente em alimentação; e por

ERUMS $=\mathrm{CMS} / \mathrm{TRU} \mathrm{e}$

ERUFDN= CFDN/TRU, em que:

ERUMS (g MS ruminada/h); ERUFDN (g FDN ruminada/h) = eficiência de ruminação e TRU $(\mathrm{h} / \mathrm{dia})=$ tempo de ruminação. O (TMT $\mathrm{min} / \mathrm{dia})$ tempo de mastigação total foi obtido por:

TMT= TAL + TRU (Bürguer et al., 2000).

Os números de períodos de alimentação, ruminação e ócio foram contabilizados pelo número de sequências de atividades observadas na planilha de anotações. A duração média diária desses períodos de atividades foi calculada dividindo-se a duração total de cada atividade alimentação, ruminação e ócio pelo seu respectivo número de períodos discretos (Silva et al., 2006).

Os dados de tempo gasto com alimentação, ruminação e ócio, os consumos de MS e FDN, as eficiências de alimentação e ruminação, o tempo de mastigação total, o número de bolos regurgitados por dia, o número de mastigações totais por dia, o número de mastigações por bolo e o tempo de ruminação por bolo foram avaliados por meio de análises de variância e de regressão. Os modelos estatísticos foram escolhidos de acordo com a significância dos coeficientes de regressão, utilizando-se o teste “ $t$ ” em nível de $5 \%$, e de determinação $\left(r^{2}\right)$, e com o fenômeno biológico estudado.

\section{RESULTADOS E DISCUSSÃO}

Houve efeito quadrático $(\mathrm{P}<0,05)$ sobre os consumos de matéria seca (CMS) e fibra em detergente neutro (CFDN), em kg/dia (Tab. 4). O aumento do consumo de MS é consequência não somente da maior ingestão de MS, com o aumento da utilização do FPAM, como também da menor participação da MS na composição química da dieta exclusiva de cana-de-açúcar (Tab. 3). Porém, esse aumento teve seu ponto de máximo CMS na quantidade de inclusão de
$59,33 \%$ do FPAM. A partir desse valor, a quantidade de lignina das dietas experimentais (Tab. 3) pode ter limitado o consumo de MS pelo enchimento ruminal, caracterizando uma limitação física. Como é sabido, a baixa degradabilidade da cana no rúmen limita a taxa de passagem ruminal e, consequentemente, resulta em baixo consumo. Detmann et al. (2003), ao investigarem o consumo de FDN por bovinos de corte confinados em condições tropicais, em razão da porcentagem de volumosos na dieta, sugeriram que a predominância de mecanismos físicos de regulação do CMS seria observada em proporção de volumosos acima de $64 \%$.

A influência do consumo de fibra sobre as atividades comportamentais pode ser confirmada pelos resultados apresentados por Oliveira et al. (2007b), que avaliaram o comportamento ingestivo de vacas em lactação de alta produção, as quais receberam silagem de milho ou cana-deaçúcar como volumoso, e verificaram que o maior consumo de FDN (7,2kg/dia), no tratamento com silagem de milho em relação ao com cana-de-açúcar $(5,0 \mathrm{~kg} / \mathrm{dia})$, fez com que os animais do tratamento com silagem de milho despendessem mais tempo nas atividades de alimentação e ruminação, sendo registrados valores de 306,0 e $246,0 \mathrm{~min} /$ dia para a atividade de alimentação e 546,0 e $438,0 \mathrm{~min} /$ dia para a atividade de ruminação, respectivamente.

No presente trabalho, mesmo com o maior consumo de FDN nos tratamentos à base de FPAM, a atividade de alimentação não diferiu entre os tratamentos. Provavelmente, o que ocorreu foi que, mesmo com o menor CFDN do tratamento exclusivo de cana-de-açúcar, a qualidade da dieta fez com que os animais tivessem a necessidade de alimentar-se por mais tempo para compensar a pior qualidade da dieta.

Houve efeito quadrático $(\mathrm{P}<0,05)$ da inclusão de FPAM sobre as atividades de ruminação, em $\mathrm{min} / \mathrm{dia}$, encontrando-se o ponto de máxima de $28,00 \%$ de inclusão, o que corresponde ao valor de 565,32 . Este resultado pode ser explicado pelo elevado teor de FDN das dietas experimentais (Tab. 3) e pelo alto CMS, sendo observados os maiores valores das atividades de ruminação, para a dieta exclusiva de cana-de-açúcar, o que é atribuído à menor qualidade da fibra presente neste alimento. 
Tabela 4. Consumo de matéria seca, fibra em detergente neutro e atividades de alimentação, ruminação, mastigação e ócio de vacas alimentadas com cana-de-açúcar ou diferentes porcentagens de feno da parte aérea da mandioca (FPAM)

\begin{tabular}{|c|c|c|c|c|c|c|c|c|c|}
\hline \multirow{3}{*}{ Item } & \multicolumn{4}{|c|}{ Inclusão do FPAM (\%) } & \multirow{3}{*}{$\begin{array}{l}\mathrm{CV} \\
(\%)\end{array}$} & \multirow{3}{*}{$\begin{array}{l}\text { Equação de } \\
\text { regressão }\end{array}$} & \multirow{3}{*}{$\begin{array}{l}\text { Mês } \\
(\%)\end{array}$} & \multirow{3}{*}{$\begin{array}{l}\text { Máx ou } \\
\text { Min }\end{array}$} & \multirow{3}{*}{$\mathrm{R}^{2}$} \\
\hline & 0 & 33 & 67 & 100 & & & & & \\
\hline & \multicolumn{4}{|c|}{ Consumo (kg/dia) } & & & & & \\
\hline CMS & 12,35 & 16,18 & 16,29 & 14,79 & 16,69 & $\begin{array}{c}\hat{\mathrm{Y}}=12,46+0,14 \mathrm{x}- \\
0,0012 \mathrm{x}^{2}\end{array}$ & 59,33 & 16,69 & 0,97 \\
\hline \multirow[t]{2}{*}{ CFDN } & 5,97 & 8,26 & 8,68 & 8,20 & 8,95 & $\begin{array}{c}\mathrm{Y}=6,02+0,08 \mathrm{x}- \\
0,0006 \mathrm{x}^{2}\end{array}$ & 69,83 & 8,95 & 0,98 \\
\hline & \multicolumn{4}{|c|}{ Alimentação } & & & & & \\
\hline \multirow[t]{2}{*}{ Min/dia } & 339,7 & 325,3 & 336,3 & 319,7 & 9,71 & $\hat{\mathrm{Y}}=330,2$ & -- & -- & -- \\
\hline & \multicolumn{4}{|c|}{ Ruminação } & & & & & \\
\hline \multirow[t]{2}{*}{ Min/dia } & 551,9 & 564,1 & 539,4 & 474,1 & 9,94 & $\begin{aligned} \hat{Y}= & 51,61+0,98 x- \\
& 0,0175 x^{2}\end{aligned}$ & 28,00 & 565,32 & 0,99 \\
\hline & \multicolumn{4}{|c|}{ Mastigação } & & & & & \\
\hline $\mathrm{N}^{\mathrm{o}} /$ bolo & 58,49 & 57,73 & 56,59 & 57,01 & 8,62 & $\hat{\mathrm{Y}}=57,46$ & -- & -- & -- \\
\hline Seg/bolo & 60,99 & 58,85 & 57,59 & 59,21 & 8,63 & $\hat{\mathrm{Y}}=59,16$ & -- & -- & -- \\
\hline $\mathrm{N}^{\mathrm{o}} / \mathrm{dia}$ & 31820 & 33442 & 32039 & 27589 & 12,22 & $\begin{array}{c}\hat{Y}=31814+95,11 x- \\
1,3732 x^{2}\end{array}$ & 34,63 & 33461 & 1,00 \\
\hline Min/dia & 891,56 & 889,31 & 875,63 & 793,75 & 7,95 & $\begin{array}{c}\hat{\mathrm{Y}}=888,58+0,88 \mathrm{x}- \\
0,0180 \mathrm{x}^{2}\end{array}$ & 24,44 & 899,34 & 0,97 \\
\hline $\begin{array}{l}\mathrm{Min} / \mathrm{kg} \\
\mathrm{MS}\end{array}$ & 73,56 & 54,71 & 55,07 & 54,82 & 9,63 & $\begin{array}{c}\hat{Y}=72,53- \\
0,59 x+0,0042 x^{2}\end{array}$ & 69,95 & 51,98 & 0,92 \\
\hline \multirow[t]{2}{*}{$\begin{array}{l}\mathrm{Min} / \mathrm{kg} \\
\mathrm{FDN}\end{array}$} & 153,04 & 103,92 & 104,53 & 98,22 & 13,72 & $\begin{array}{c}\hat{Y}=150,11- \\
1,46 x+0,0097 x^{2}\end{array}$ & 75,14 & 95,35 & 0,91 \\
\hline & \multicolumn{4}{|c|}{ Ócio } & & & & & \\
\hline Min/dia & 547,5 & 550,6 & 564,1 & 645,9 & 11,91 & $\begin{array}{c}\hat{Y}=550,56- \\
0,86 x+0,0178 x^{2}\end{array}$ & 24,09 & 540,23 & 0,97 \\
\hline
\end{tabular}

CV- coeficiente de variação; Mês (\%) - porcentagem máxima de inclusão; Max ou Min - ponto de máxima ou mínima estimado; $\mathrm{R}^{2}$ - coeficiente de regressão.

Apesar de a cana-de-açúcar apresentar elevada fração A (açúcares solúveis), o que, provavelmente, suportaria rápido crescimento microbiano no rúmen, ela apresenta baixa taxa de degradação ruminal da fibra potencialmente degradável (B2), com considerável efeito de repleção (Pereira et al., 2001), o que proporciona redução da ingestão de MS e da disponibilidade de energia.

O maior tempo gasto com ruminação nos tratamentos que incluíram cana-de-açúcar nas dietas está de acordo com os resultados descritos por Van Soest (1994), ao afirmarem que o tempo gasto com a ruminação foi influenciado pela natureza da dieta e parece ser proporcional ao teor de parede celular dos volumosos.

No presente trabalho, a atividade de ruminação diferiu da obtida por Rabelo et al. (2008), ao afirmarem que a média de tempo gasto diariamente com a ruminação foi de, aproximadamente, 320 $\mathrm{min} / \mathrm{dia}$, variando conforme a porcentagem de FDN da dieta. Essa diferença de valores pode ser atribuída à dieta do presente trabalho, que teve como volumosos a cana-de-açúcar e o FPAM, com alta porcentagem de FDN (Tab. 2), os quais fizeram com que as porcentagens de FDN da dieta ficassem acima dos $35 \%$ normalmente utilizados para vacas em lactação.

A elevada proporção de cana-de-açúcar e FPAM utilizada no presente estudo, volumosos com elevado teor de fibra de baixa ou lenta digestão, não foi capaz de causar efeito significativo $(\mathrm{P}>0,05)$ sobre as atividades de mastigação, como número e tempo médio despendido em mastigações por bolo e tempo médio de mastigação total (seg/bolo), sendo observados valores médios de 57,46 mastigações/bolo e 59,19 seg/bolo, respectivamente. Segundo Queiroz et al. (2001), alimentos com alto teor de FDN ou FDN de baixa degradabilidade necessitam ser mastigados e, principalmente, ruminados por mais tempo. 
Houve efeito quadrático da inclusão de FPAM $(\mathrm{P}<0,05)$ sobre as atividades de mastigação, sendo encontrado, para o número de mastigações por dia e o tempo gasto em $\mathrm{min} / \mathrm{dia}$, o ponto de máxima em 34,6 e 24,4\%, respectivamente, de inclusão do FPAM, o que corresponde aos valores de 33460 mastigações/dia e $899,34 \mathrm{~min} / \mathrm{dia}$, respectivamente, para as atividades de mastigação, em $\mathrm{min} / \mathrm{kg}$ de MS e $\mathrm{min} / \mathrm{kg}$ de FDN. Os pontos de mínima encontrados foram de 69,9 e $75,1 \%$, o que corresponde aos valores de 51,98 e $95,35 \mathrm{~min} / \mathrm{kg}$ de MS e FDN, respectivamente. $\mathrm{O}$ efeito quadrático observado para as atividades de mastigação já era esperado pelo fato de essa variável ser diretamente relacionada com as atividades de ruminação e alimentação, e à medida que se incluiu FPAM, as atividades de ruminação e alimentação foram diminuindo, o que teve efeito direto nas atividades de mastigação.

Houve efeito quadrático da inclusão de FPAM $(\mathrm{P}<0,05)$ sobre as atividades de ócio, o que já era esperado pelo fato de essa variável ser diretamente relacionada com as atividades de ruminação e alimentação, pois à medida que a cana-de-açúcar foi sendo substituída pelo FPAM, as atividades de alimentação e ruminação diminuíram e consequentemente, restou mais tempo para o animal permanecer em ócio. $\mathrm{O}$ comportamento de ócio constitui o período em que os animais não se alimentam, ruminam ou ingerem. $\mathrm{O}$ valor encontrado para esta variável foi de $540,23 \mathrm{~min} /$ dia para o ponto de mínima, o que corresponde à inclusão de $24,1 \%$.

Houve efeito quadrático da inclusão de FPAM $(\mathrm{P}<0,05)$ sobre a eficiência de alimentação (EAL), em g MS/hora e g de FDN/hora, observando-se para os pontos de máxima valores de $3171 \mathrm{~g} \mathrm{MS/hora} \mathrm{e} \mathrm{1723g} \mathrm{FDN/hora,} \mathrm{o} \mathrm{que}$ corresponde à de inclusão de 60,1 e 63,8\%, respectivamente. Os valores observados seguem a mesma tendência do CMS e CFDN (Tab. 4), em razão de a variável avaliada ser dependente, o que mostra a melhor qualidade das dietas com a associação da cana-de-açúcar e o FPAM, que foram as que apresentaram a melhor eficiência, sendo observados, nestes dois tratamentos, os maiores CMS e, consequentemente, de FDN.

As dietas com associação cana-de-açúcar e FPAM e a dieta exclusiva de FPAM proporcionaram maior ingestão de MS, requerendo, por parte do animal, menor tempo total de ingestão por $\mathrm{kg}$ de MS, caracterizando, dessa forma, uma melhor eficiência de alimentação e ruminação em razão do CMS. Pereira et al. (2007), ao trabalharem com diferentes teores de FDN na dieta, relataram que a EAL foi menor quando os valores de FDN foram maiores, passando de 2980 para $2210 \mathrm{~g}$ de MS/hora quando se aumentou de 30 para $60 \%$ de FDN na dieta.

Houve efeito quadrático da inclusão de FPAM $(\mathrm{P}<0,05)$ sobre a eficiência de ruminação (ER) em número de bolos/dia ( $\left.\mathrm{n}^{\circ} / \mathrm{dia}\right), \mathrm{g}$ de MS/hora e g de FDN/hora, observando-se, para estas variáveis, o ponto de máxima na inclusão de 37,$6 ; 79,2$ e $80,9 \%$, respectivamente, o que corresponde aos valores de 587 bolos/dia; 1933g de MS/hora e 1060g de FDN/hora, respectivamente (Tab. 5). O número de bolos ruminados diariamente, que variou entre $490 \mathrm{e}$ 584, apresentou-se acima do valor relatado por Oliveira et al. (2007b), de 472 bolos/dia, em dieta à base de cana-de-açúcar e concentrado. Essa diferença pode ser atribuída à maior quantidade de concentrado no trabalho citado.

Os dados referentes ao número de períodos de alimentação, ruminação e ócio não apresentaram diferença $(\mathrm{P}>0,05)$ entre os tratamentos (Tab. 6). Carvalho et al. (2008) comentam que o consumo diário de alimentos pode ser descrito pelo número de refeições consumidas por dia, pela duração e pela taxa de alimentação, a qual é representada pela velocidade em que cada refeição é feita. Segundo Silva et al. (2005), o padrão de procura de alimentos por bovinos confinados é bem característico, com dois momentos principais: início da manhã e final da tarde.

Mendes Neto et al. (2007) afirmaram que a modificação no horário ou na frequência de fornecimento da dieta ao animal pode modificar a distribuição percentual dos horários de alimentação de animais em confinamento. Por isso, no presente estudo, não foi verificada diferença no número de períodos de alimentação, ruminação e ócio, uma vez que as dietas eram rigorosamente fornecidas no mesmo horário, todos os dias, às sete e às 16 horas. 
Tabela 5. Eficiência de alimentação e ruminação de vacas alimentadas com cana-de-açúcar ou diferentes porcentagens de feno da parte aérea da mandioca (FPAM)

\begin{tabular}{|c|c|c|c|c|c|c|c|c|c|}
\hline \multirow{3}{*}{ Item } & \multicolumn{4}{|c|}{ Inclusão do FPAM (\%) } & \multirow{3}{*}{$\begin{array}{l}\mathrm{CV} \\
(\%)\end{array}$} & \multirow{3}{*}{ Equação de regressão } & \multirow{3}{*}{$\begin{array}{l}\text { Mês } \\
(\%)\end{array}$} & \multirow{3}{*}{$\begin{array}{l}\text { Máx } \\
\text { ou } \\
\text { Min }\end{array}$} & \multirow{3}{*}{$\mathrm{R}^{2}$} \\
\hline & 0 & 33 & 67 & 100 & & & & & \\
\hline & \multicolumn{4}{|c|}{ Eficiência de alimentação } & & & & & \\
\hline $\mathrm{g}$ de MS/hora & 2242 & 3153 & 3000 & 2840 & 12,67 & $\begin{array}{l}\hat{Y}=2296,60+29,11 x- \\
0,2421 x^{2}\end{array}$ & 60,11 & 3171 & 0,88 \\
\hline \multirow[t]{2}{*}{$\mathrm{g}$ de FDN/hora } & 1081 & 1702 & 1604 & 1570 & 18,85 & $\begin{array}{l}\hat{Y}=1121,56+18,88 x- \\
0,1480 x^{2}\end{array}$ & 63,78 & 1723 & 0,86 \\
\hline & \multicolumn{4}{|c|}{ Eficiência de ruminação } & & & & & \\
\hline Bolos (n /dia) & 553 & 584 & 569 & 490 & 14,10 & $\begin{array}{l}\hat{Y}=552,66+1,86 x- \\
0,0247 x^{2}\end{array}$ & 587 & 37,65 & 0,99 \\
\hline $\mathrm{g}$ de MS/hora & 1361 & 1781 & 1882 & 1908 & 14,63 & $\begin{array}{l}\hat{Y}=1373,67+14,12 x- \\
0,0891 x^{2}\end{array}$ & 1933 & 79,24 & 0,98 \\
\hline g de FDN/hora & 660 & 966 & 1007 & 1053 & 21,71 & $\begin{array}{l}\hat{Y}=674,52+9,53 x- \\
0,0589 x^{2}\end{array}$ & 1060 & 80,95 & 0,95 \\
\hline
\end{tabular}

CV- coeficiente de variação; MÊS (\%) - porcentagem máxima de inclusão, Max ou Min - ponto de máxima ou mínima estimado; $\mathrm{R}^{2}$ - coeficiente de regressão.

Tabela 6. Número e tempo médio despendido por período nas atividades de alimentação, ruminação e ócio e consumo de MS e FDN por período de alimentação de vacas alimentadas com cana-de-açúcar ou diferentes porcentagens de feno da parte aérea da mandioca (FPAM)

\begin{tabular}{|c|c|c|c|c|c|c|c|c|c|}
\hline \multirow{3}{*}{ Item } & \multicolumn{4}{|c|}{ Inclusão do FPAM (\%) } & \multirow{3}{*}{$\begin{array}{l}\mathrm{CV} \\
(\%)\end{array}$} & \multirow{3}{*}{ Equação e valores médios } & \multirow{3}{*}{$\begin{array}{l}\text { Mês } \\
(\%)\end{array}$} & \multirow{3}{*}{$\begin{array}{l}\text { Máx ou } \\
\text { Min }\end{array}$} & \multirow{3}{*}{$\mathrm{R}^{2}$} \\
\hline & 0 & 33 & 67 & 100 & & & & & \\
\hline & \multicolumn{4}{|c|}{ Número de períodos ( $\left.\mathrm{n}^{\circ} / \mathrm{dia}\right)$} & & & & & \\
\hline Alimentação & 13,50 & 12,69 & 12,81 & 12,44 & 20,76 & $\hat{\mathrm{Y}}=12,86$ & -- & -- & -- \\
\hline Ruminação & 18,69 & 19,13 & 17,38 & 17,50 & 15,45 & $\hat{\mathrm{Y}}=18,17$ & -- & -- & -- \\
\hline \multirow[t]{2}{*}{ Ócio } & 24,00 & 25,25 & 24,13 & 24,06 & 14,49 & $\hat{Y}=24,36$ & -- & -- & -- \\
\hline & \multicolumn{4}{|c|}{ Tempo gasto por período $(\mathrm{min})$} & & & & & \\
\hline Alimentação & 26,36 & 28,71 & 29,07 & 27,09 & 24,58 & $\hat{Y}=27,81$ & -- & -- & -- \\
\hline Ruminação & 30,58 & 30,32 & 32,10 & 27,54 & 16,08 & $\hat{Y}=30,13$ & -- & -- & -- \\
\hline \multirow[t]{2}{*}{ Ócio } & 24,18 & 22,83 & 24,23 & 27,64 & 21,02 & $\hat{Y}=24,72$ & -- & -- & -- \\
\hline & \multicolumn{4}{|c|}{$\begin{array}{c}\text { Consumo médio por período de } \\
\text { alimentação }(\mathrm{kg})\end{array}$} & & & & & \\
\hline MS & 0,984 & 1,428 & 1,383 & 1,261 & 23,46 & $\begin{array}{c}\hat{Y}=1,0048+0,0152 x- \\
0,0001 x^{2}\end{array}$ & 76,00 & 1,58 & 0,92 \\
\hline FDN & 0,475 & 0,758 & 0,733 & 0,696 & 24,77 & $\begin{array}{c}\hat{\mathrm{Y}}=0,4901+0,0091 \mathrm{x}- \\
0,0001 \mathrm{x}^{2}\end{array}$ & 45,50 & 0,70 & 0,91 \\
\hline
\end{tabular}

CV- coeficiente de variação; Mês (\%) - porcentagem máxima de inclusão, Max ou Min - ponto de máxima ou mínima estimado; $\mathrm{R}^{2}$ - coeficiente de regressão.

Os tempos de duração de cada período de alimentação, ruminação e ócio não sofreram efeito $(\mathrm{P}>0,05)$ da inclusão do FPAM. Salla et al. (2003) relataram, em vacas Jersey, valor de 26 minutos por período de ruminação, o qual se mostrou semelhante ao do presente estudo, que foi de 27,81 minutos. Os animais do tratamento exclusivo de cana-de-açúcar gastaram menos tempo com a alimentação, porém precisaram alimentar-se mais vezes para suprir suas exigências. Isto acontece porque, sendo a qualidade da fibra presente na cana-de-açúcar de baixa degradabilidade, à medida que pequenas porções dos alimentos vão sendo degradadas e direcionadas ao próximo compartimento, o compartimento anterior é liberado para ingestão de mais alimentos, que são consumidos em pequenas quantidades.

Houve efeito quadrático da inclusão de FPAM $(\mathrm{P}<0,05)$ sobre o consumo médio diário de MS e FDN por período de alimentação, sendo observados, para o ponto de máxima 76,0 e $45,5 \%$ de inclusão, o que corresponde aos valores de 1,58 e $0,70 \mathrm{~kg}$ de MS e FDN consumidos por período de alimentação, respectivamente. Com a diferença entre os consumos de MS e FDN (Tab. 4) observados entre as dietas experimentais, era de se esperar 
diferença entre os valores de consumo por período de alimentação.

\section{CONCLUSÕES}

Os tempos despendidos em ruminação, mastigação e ócio apresentaram efeito quadrático com a inclusão do feno da parte aérea da mandioca. A inclusão do feno na dieta influenciou quadraticamente o consumo de MS e FDN, que influenciaram também de forma quadrática a eficiência de alimentação e ruminação.

\section{REFERÊNCIAS}

BÜRGER, P.J.; PEREIRA, J.C.; QUEIROZ, A.C. et al. Comportamento ingestivo em bezerros holandeses alimentados com dietas contendo diferentes níveis de concentrado. Rev. Bras. Zootec., v.29, p.236-242, 2000.

CARVALHO, G.G.P.; PIRES, A.J.V.; SILVA, R.R. et al. Comportamento ingestivo de ovinos Santa Inês alimentados com dietas contendo farelo de cacau. Rev. Bras. Zootec., v.37, p.660-665, 2008.

DADO, R.G.; ALLEN, M.S. Intake limitations, feeding behavior, and rumen function of cows challenged with rumen fill from dietary fiber or inert bulk. J. Dairy Sci., v.78, p.118-133, 1995.

DETMANN, E.; PINA, D.S.; VALADARES FILHO, S.C. et al. Estimação da fração digestível da proteína bruta em dietas para bovinos em condições brasileiras. Rev. Bras. Zootec., v.35, p.2101-2109, 2006 a.

DETMANN, E.; QUEIROZ, A.C.; CECON, P.R. et al. Consumo de fibra em detergente neutro por bovinos em confinamento. Rev. Bras. Zootec., v.32, p.1763-1777, 2003.

DETMANN, E.; SOUZA, A.L.; GARCIA, R. et al. Avaliação do "vício de tempo" de indicadores internos em ensaio de digestão com ruminantes. Arq. Bras. Med. Vet. Zootec., v.59, p.182-188, 2007b.

DETMANN, E.; VALADARES FILHO, S.C.; HENRIQUES, L.T. et al. Estimação da digestibilidade dos carboidratos não-fibrosos em bovinos utilizandose o conceito de entidade nutricional em condições brasileiras. Rev. Bras. Zootec., v.35, p.1479-1486, 2006c.

DETMANN, E.; VALADARES FILHO, S.C.; HENRIQUES, L.T. et al. Reparametrização do modelo baseado na lei de superfície para predição da fração digestível da fibra em detergente neutro em condições brasileiras. Rev. Bras. Zootec., v.36, p.155$164,2007 \mathrm{a}$.
DETMANN, E.; VALADARES FILHO, S.C.; PINA, D.S. et al. Estimação da digestibilidade do extrato etéreo em ruminantes a partir dos teores dietéticos: desenvolvimento de um modelo para condições brasileiras. Rev. Bras. Zootec., v.35, p.1469-1478, $2006 \mathrm{~b}$

MARQUES, J.A.; CALDAS NETO, S.F. Mandioca na alimentação Animal: Parte Aérea e Raiz. Campo Mourão - PR. CIES, 28p. 2002.

MENDES NETO, J.; CAMPOS, J.M.S.; VALADARES FILHO, S.C. et al. Comportamento ingestivo de novilhas leiteiras alimentadas com polpa cítrica em substituição ao feno de capim-tifton 85 . Rev. Bras. Zootec., v.36, p.618-625, 2007.

MENDONÇA, S.S.; CAMPOS, J.M.S.; VALADARES FILHO, S.C. et al. Comportamento ingestivo de vacas leiteiras alimentadas com dietas à base de cana de-açúcar ou silagem de milho. Rev. Bras. Zootec., v.33, p.723-728, 2004.

MODESTO, E.C.; SANTOS, G.T.; VILELA, D. et al. Caracterização químico - bromatológica da silagem do terço superior da rama de mandioca. A. Scient., v.26. p.137-146. 2004.

NUTRIENT requirements of dairy cattle. 7 th ed. Washington, DC: National Academy, 2001. 381p.

OLIVEIRA, A.S.; CAMPOS, J.M.S.; VALADARES FILHO, S.C. et al. Substituição do milho por casca de café ou de soja em dietas para vacas leiteiras: consumo, digestibilidade dos nutrientes, produção e composição do leite. Rev. Bras. Zootec., v.36, p.11721182, 2007a.

OLIVEIRA, A.S.; CAMPOS, J.M.S.; VALADARES FILHO, S.C. et al. Substituição do milho pela casca de café ou de soja em dietas para vacas leiteiras: comportamento ingestivo, concentração de nitrogênio ureico no plasma e no leite, balanço de compostos nitrogenados e produção de proteína microbiana. Rev. Bras. Zootec., v.36, p.205-215, 2007 b.

PEREIRA, J.C.; CUNHA, D.N.F.V.; CECON, P.R. et al. Comportamento ingestivo e taxa de passagem de partículas em novilhas leiteiras de diferentes grupos genéticos submetidas a dietas com diferentes níveis de fibra. Rev. Bras. Zootec., v.36, p.2134-2142, 2007.

PEREIRA, E.S.; QUEIROZ, A.C.; PAULINO, M.F. et al. Fontes nitrogenadas e uso de Sachoromyces cerevisiae em dietas à base de cana-de-açúcar para novilhos: consumo, digestibilidade, balanço nitrogenado e parâmetros ruminais. Rev. Bras. Zootec., v.30, p.563-572, 2001.

QUEIROZ, A.C.; NEVES, J.S.; MIRANDA, L.F. et al. Efeito do nível de fibra e da fonte de proteína sobre o comportamento alimentar de novilhas mestiças Holandês-Zebu. Arq. Bras. Med. Vet. Zootec., v.53, p.84-88, 2001. 


\section{Rocha Neto et al.}

RABELO, M.M.A.; PIRES, A.V.; SUSIN, C.Q. et al. Avaliação do efeito do bagaço de cana-de-açúcar in natura obtido por dois métodos sobre o desempenho e o comportamento ingestivo de bovinos de corte. Arq. Bras. Med. Vet. Zootec., v.60, p.698-704, 2008.

SALLA, L.E.; FISCHER, V.; FERREIRA, E.X. et al Comportamento ingestivo de vacas Jersey alimentadas com dietas contendo diferentes fontes de gordura nos primeiros 100 dias de lactação. Rev. Bras. Zootec. v.32, p.683-689, 2003.

SILVA, D.J.; QUEIROZ, A.C. Análise de alimentos: métodos químicos e biológicos. 2.ed. Viçosa, MG: UFV, 2002. 165p.
SILVA, R.R.; SILVA, F.F.; CARVALHO, G.G.P. et al. Comportamento ingestivo de novilhas mestiças de holandês x zebu confinadas. Arch. Zootec., v.54, p.75$85,2005$.

SILVA, R.R.; SILVA, F.F.; PRADO, I.N. et al. Comportamento ingestivo de bovinos. Aspectos metodológicos. Arch. Zootec., v.55, p.293-296, 2006.

SNIFFEN, C.J.; O'CONNOR, D.J.; Van SOEST, P.J. et al. A net carbohydrate and protein system for evaluating cattle diets: carbohydrate and protein availability. J. Anim. Sci., v.70, p.3562-3577, 1992.

Van SOEST, P.J. Nutritional ecology of the ruminant. 2nd ed. Ithaca: Cornell, 1994. 476p. 